\title{
Science and Religion: Compatible or Incompatible Explanatory Realms? ${ }^{1}$
}

\section{Kirk Fitzhugh ${ }^{2}$}

\begin{abstract}
Among portrayals of evolutionary biology and intelligent design, some evolutionary biologists and organizations have claimed religion and science are compatible, commonly referred to as accommodationism. This claim is, from the perspective of science, wholly incorrect. While religion and science are similar in that both seek causal explanations for natural phenomena, this does not render the two approaches compatible or not in conflict. The sciences seek causal understanding by way of theories and hypotheses that ensure understanding is open to critical, empirical evaluation. Reliance on supernatural-based theories and hypotheses are operationally (as opposed to technically) immune to such testing. For religion and science to exist in a complementary state, religious theories and hypotheses would have to be limited to explaining non-empirical, supernatural phenomena, while scientific theories and hypotheses are applied to natural phenomena. The opportunity for asymmetrical causal overlap is obviated.
\end{abstract}

Key words: accommodationism, evolution, hypothesis testing, religion, scientific reasoning

\section{Introduction}

On the topic of the intersection between evolutionary biology and religion, including intelligent design ${ }^{3}$ (ID), the anonymous contributors from the National Academies of Science and Institute of Medicine's (2008a:49; see also American Association for the Advancement of Science 2006, 2011; National Academies 2008b; Ecklund and Park 2009; Ecklund 2010) publication on evolution and creationism states that,

\footnotetext{
${ }^{1}$ Submitted on September 1, 2018. Accepted on October 17, 2018. Last revisions received on October 31, 2018. This manuscript is not about religion per se. Instead, it addresses the fact that religion sensu supernatural causation is at odds with scientific inquiry. This paper does not address every possible permutation of religion to address the fact that science and religion are not compatible from the perspective of science. Furthermore, there is no reason to entertain religious naturalism since there is nothing religious about the position. Also, the notion that God operates through natural causation is to interpret God as a causal agent acting on natural phenomena. Resorting to saying God operates through natural causes is evasion of the issue at hand, and from a scientific perspective leaves the notion toothless and unnecessary to consider.

2 Research and Collections Branch, Natural History Museum of Los Angeles County, 900 Exposition Boulevard, Los Angeles, California 90007 USA. E-mail: kfitzhugh@nhm.org .

${ }^{3}$ Contrary to claims often promulgated by intelligent design (ID) advocates (e.g., Meyer 2013), that the 'designer' to which they refer is not necessarily a supernatural entity (but see Meyer 1999), the arguments in this essay apply to that movement. ID has never presented a cogent theory of a designer from which one can entertain testing such a theory (Fitzhugh 2010), leaving consideration of the subject on par with religious-based supernatural theories.
}

DOI: 10.9784/LEB6(1)Fitzhugh.01

Electronically available on October 31, 2018. Mailed on October 31, 2018. 


\begin{abstract}
"Newspaper and television stories sometimes make it seem as though evolution and religion are incompatible, but that is not true. Many scientists and theologians have written about how one can accept both faith and the validity of biological evolution."
\end{abstract}

In a similar vein, Ayala (2006:90; 2008; see also Avise 2010a, 2010b; Martin 2010) asserts that "the theory of evolution is not incompatible with belief in the existence of God and God's presence in the workings of the universe." That compatibility is, according to Ayala (2007:ix), a matter of different goals between science and religion:

"Science and religious beliefs need not be in contradiction. If they are properly understood [sic], they cannot be in contradiction because science and religion concern different matters. Science concerns the processes that account for the natural world: how the planets move, the composition of matter and the atmosphere, the origin and function of organisms. Religion concerns the meaning and purpose of the world and of human life, the proper relation of people to their Creator and to each other, the moral values that inspire and govern people's lives."

There is a supposed asymmetry that seals the notion of compatibility: "Scientific knowledge cannot contradict religious beliefs because science has nothing to say for or against revelation, religious realities, or religious values" (Ayala 2006:103). Similar advocacy for compatibility can be found on federallyfunded internet web sites, written by anonymous collaborators, such as the University of California at Berkeley's Understanding Science: How Science Really Works (University of California Museum of Paleontology 2009a: Science and religion: reconcilable differences): “...people of many different faiths and levels of scientific expertise see no contradiction at all between science and religion," and Understanding Evolution (University of California Museum of Paleontology 2009b: Misconceptions about Evolution and the Mechanisms of Evolution): "...most religious groups have no conflict with the theory of evolution or other scientific findings." Gould's (1999) "non-overlapping magisteria", or NOMA, concept has received wide attention for the view that science and religion operate in close but separate harmony.

The difficulty with the perspective that science and religion are compatible, what has become known as accommodationism (Coyne 2012), is that it can only succeed by allowing the asymmetry quoted above by Ayala (2006). God, or any 
other type of supernatural entity ${ }^{4}$, is a relevant and exclusive causal factor for some natural phenomena, e.g., "the meaning and purpose of the world and of human life, the proper relation of people to their Creator and to each other, the moral values that inspire and govern people's lives," and science is relegated to other natural phenomena. Asserting that there are respective theories of existence of supernatural entities and their behaviors that have exclusive causal/explanatory roles to play about certain natural, empirical phenomena is an epistemic claim. As such, there is an operational equivalence between causes that are supernatural and natural, and thus we should expect de facto epistemic equivalence between the two causal realms. This equivalence would then necessitate that judging the veracity of a supernatural-based theory as causally relevant for natural phenomena would have to be on par with how theories of natural cause-effect relations are assessed in the sciences. Advocates of accommodationism would have to empirically establish that the sciences are not capable of addressing, potentially or otherwise, certain natural phenomena in lieu of reliance on the supernatural.

Can the accepted and established foundations for the scrutiny of empirical theories and hypotheses allow for the compatibility endorsed by Ayala, Gould, and some other evolutionary biologists and organizations? The goal of this paper is to point out that to impose such compatibility presents unrealistic constraints on the nature of scientific inquiry. By the very protocols by which such inquiry proceeds as a mechanism to acquire causal understanding, laying open theories and hypotheses to empirical evaluation, to say that supernatural causes are efficacious alternatives to natural causes does not stand as a matter of compatibility. In fact, asserting compatibility is contradictory to the very nature of science. Ayala (2007:ix) was quoted earlier that if science and religion are "properly understood, they cannot be in contradiction because science and religion concern different matters." This paper will show that properly understanding scientific inquiry, considering the inferential processes required during such inquiry, leads one to the opposite conclusion. Ironically, regarding this same passage, Behe (2008:147; see also Moritz 2009) correctly points out that "if religious claims appear to call for alternative scientific conclusions, then clearly the two disciplines do sometimes significantly overlap, despite Ayala's claims."

\footnotetext{
${ }^{4}$ I follow Boudry et al.'s (2010:233) definition of supernatural: “...any phenomenon which has its basis in entities and processes that transcend the spatiotemporal realm of impersonal matter and energy described by modern science....." This does not preclude one from suggesting events arise via both natural and supernatural causes, but what is presented in this paper is thatbasic principles of scientific inquiry deny the opportunity to invoke supernatural causes. Accommodationism in toto is contradictory to the foundations of science. We have no way to evaluate what is allowed by accommodationism and it does not enhance our understanding.
} 


\section{Compatibility versus Incompatibility}

In fairness to science and religion, to speak of these realms as either compatible or incompatible, to whatever extent, requires acknowledging two aspects of both: their respective goals and the manners, if any, by which each engages in evaluative processes of their respective theories and the hypotheses that result from applications of those theories. For this paper, I will restrict reference to 'religion' to only the main western religions, namely, Judaism, Christianity, and Islam. As will be discussed in this section, science and religion do have at least partially parallel goals when we consider the natural realm. Yet it is the mechanisms for attaining their goals and evaluations of the processes for realizing those goals that are distinctly incompatible when the available causal alternatives are natural- versus supernatural-based theories and hypotheses.

\section{Compatibility between science and religion}

Regarding the natural, empirical realm, religion and science have the same intent: to causally account for objects and events we perceive. The range of such phenomena can be as broad as the nature of the universe, to smaller scales, like human ethics, behavior, and other cognitive functions ${ }^{5}$. For instance, in his definition of religion, Geertz (1993:90, emphasis original) states that it is,
“(1) a system of symbols which acts to (2) establish powerful, pervasive, and long-lasting moods and motivations in men by (3) formulating conceptions of a general order of existence and (4) clothing these conceptions with such an aura of factuality that (5) the moods and motivations seem uniquely realistic."

The symbols and conceptions to which Geertz refers principally pertain to gods or other sorts of supernatural entities. What is relevant to the present discussion is that those symbols are not only used in the formulation of conceptions regarding those entities, but also the intersections of those entities with nature-at-large to effect causes. At least, regarding western religions and the emphasis on God, Shermer (2000:143) concludes that religion serves to provide humans with explanations of natural phenomena. Dow (2007:10) characterizes religion as a "...body of behavior unified by our failure to find a simple rational explanation for it when seen from the perspective of the individual." The behaviors Dow refers to comprise three forms, or "modules:" (1) conceptions of unobservable entities, (2) identifying particular objects, actions, principles, etc., as sacred, and (3) the actions of community sacrifice by individuals. From an evolutionary perspective, Dow regards behavior (1), the

\footnotetext{
${ }^{5}$ Science can give us understanding of meaning or purpose as well as morality. Ethics, beauty, meaning are material, human cognitive actions. They reside in the workings of neurons and neurochemistry. Thus, they do not lie beyond scientific inquiry (Thagard 2010).
} 
conjuring of such unobserved entities as gods, ghosts, demons, and angels to be an extension of the adaptive behavior among members of other animal species for reasoning that unobserved things are present in particular situations, such as predators. The selective advantages of such reasoning are clear, even when extended to the development of human social systems (cf., Pyysiäinen and Hauser 2010).

In the case of natural phenomena intersecting with God or other supernatural entities, this subsumes a system of theories that individuals apply to objects and events for acquiring some level of causal understanding of what they encounter. The tendency will be for individuals to demarcate those effects explicable by supernatural-mediated causes as opposed to natural or empirical causes. But individuals have the added luxury of playing supernatural- and empirically-based theories off one another to any extent desired (see below) for the purposes of seeking causal understanding.

Like religion, the sciences seek to acquire causal understanding of objects and events (Hempel 1965; Rescher 1970; Popper 1983, 1992; Salmon 1984a; Van Fraassen 1990; Mahner and Bunge 1997; Hausman 1998; de Regt et al. 2009). In contrast to religion, however, the sciences rely on empiricallygrounded theories, and within that class, theories that can be either potentially or have actually survived critical evaluation by way of testing. About their mutual goals, religion and science are compatible. Both encompass classes of theories that are invoked when causal questions are asked, leading to explanatory accounts that satisfy the intrinsic needs of the inquirer. But this compatibility is compromised by the fact that a causally relevant factor in religion is the action of supernatural entities on natural phenomena, supplemented by natural causes according to one's motivations. The sciences, on the other hand, impose strict limits to only empirical theories and hypotheses. This allows for some semblance of independence between science and religion, as noted by Ruse (2008:167): “...science and religion are independent in that they are not dependent on each other for their conclusions." But as will be discussed in the next section, opting for explanations of natural phenomena by way of supernatural-based causes inevitably leads to juxtaposing those with empirically testable causes. This leads to an untenable contradiction relative to scientific inquiry.

\section{Incompatibility between science and religion}

The compatibility between science and religion identified in the previous section is largely superficial in terms of explanatory frameworks. To better determine the worthiness of the accommodationist thesis asserted by some biologists and organizations requires looking at an important nuance to the difference between scientific and religious explanations. While science and religion seek causal understanding of natural phenomena, science attaches to that notion the view that such understanding, in the form of theories and 
hypotheses, should be continually open to empirical scrutiny, and updating or replacement as required by the presence of test evidence. It is the view that scientific inquiry and attendant understanding is always fallible. The dynamic nature of descriptive and causal understanding that has developed in the sciences is consistent with the very nature of human inquisitiveness. Even from an evolutionary perspective, having a constant desire to push inquiry beyond its bounds can be seen as having the selective advantage of enhancing one's ability to comprehend and manipulate their surroundings, and anticipate future consequences with a higher fidelity of success. Religion on the other hand, in the context of resorting to the supernatural as the relevant causal realm, will provide one with a level of immediate understanding that cannot be enhanced beyond the scope of accepting 'on faith' a particular theory or hypothesis of a causal relation involving supernatural entities. The consequence is that the standards for causal inquiry in the sciences are significantly different from those in religion. Science requires that theories and hypotheses be available to at least potential, critical and empirical evaluation as opposed to uncontested acceptance. Theories present general cause-effect relations, and hypotheses offer specific, spatio-temporally localized explanatory accounts (Hull 1974; Fitzhugh 2008a, 2010). For either type of proposition in the sciences, it is the fact that empirical causes are invoked that allows for confirming or disconfirming evidence to be sought. The difficulty faced by religious qua supernatural theories, and some associated hypotheses, is that the evidence required for their assessment per the standards in the sciences would not be possible. Our perceptual abilities are only able to register empirical phenomena as the rational means to critically evaluate competing theories and hypotheses. There are no epistemic opportunities to evaluate the comparative utility of scientific and religious theories as alternative, much less compatible, causal constructs (Dawes 2009). Problems for accommodationism loom large.

\section{Causal Reasoning and Demise of Accommodationism}

At this juncture, we can identify the specific basis for the incompatibility that exists between religion and science. This incompatibility is a consequence of the asymmetry in the nature of causal inquiry required in the sciences as opposed to religion. In other words, the sciences deal in empirical causation whereas religions can alternate with impunity between causes that are natural or supernatural. As such, it is causal reasoning that is at the heart of the falsity of the accommodationism thesis, discussed next.

The perception of surprising or unexpected effects leads to asking causal questions of the form, "Why $y$, in contrast to $x$ ?" (Salmon 1984b, 1989; Sober 1986, 1994; van Fraassen 1990; Lipton 2004; Fitzhugh 2006a, 2006b, 2006c, 2008 b, 2006c, 2009, 2016). In other words, the question is asked because observed effects of type $y$ were not anticipated, thus not already part of some 
expected explanatory framework that has already been applied to effects of type $x$. The mode of reasoning employed to provide at least tentative answers to such why-questions is known as abductive inference or abduction (sensu Peirce 1878, 1931-1935, 1958; Hanson 1958; Harman 1965; Achinstein 1970; Fann 1970; Reilly 1970; Curd 1980; Nickles 1980; Thagard 1988; BenMenahem 1990; Lipton 2004; Josephson and Josephson 1994; McMullin 1995; Hacking 2001; Magnani 2001; Douven 2002; Psillos 2002; GodfreySmith 2003; Walton 2004; Aliseda 2006; see Fitzhugh 2005a, 2005b, 2006a, 2006b, 2006c, 2008a, 2008b, 2008c, 2009, 2010, 2016 for considerations of abduction in relation to biological systematics and evolutionary biology). While formal logic texts traditionally segregate reasoning under the headings of deduction and induction (Salmon 1967, 1984b; Copi and Cohen 1998), where any form of reasoning that does not conform to the rules of deduction is by default inductive, there has been a movement since the 19th century to recognize that inquiry, at least in the sciences, requires a more nuanced approach. At a minimum, scientific inquiry involves the following actions subsequent to the formulations of causal questions (Peirce 1878, 1931-1935, 1958; Fitzhugh 2006a, 2008a, 2010): (1) inference of a tentative explanatory hypothesis, as answer to a question; (2) predicting consequences (potential test evidence) from that hypothesis that should be observed given the truth of the causal conditions presented in proposition; and (3) putting oneself, as the act of testing, in a position to witness the conditions that allow for observing whether or not predicted consequences derived from (2) are manifested or not. The mode of reasoning involved in (1) is abductive, that in (2) deductive, while (3) is inductive sensu stricto.

Abductive reasoning [action (1) above] is represented by the schematic form,

[1] - Auxiliary theory(ies)

- Theory $X$ : if cause $x$ occurs, effect $y$ will ensue

- Surprising effect $e_{\mathrm{y}}$ is observed

- Hypothesis $h_{\mathrm{x}}-$ cause $x$ occurred.

Inferences leading to potential test consequences (deduction) and testing proper (induction) of the hypothesis $h_{\mathrm{x}}$ inferred in [1] would have the respective forms: 
[2] • Auxiliary theory(ies)

- Theory $X$ : if cause $x$ occurs, effect $y$ will ensue

- Given hypothesis $h_{\mathrm{x}}$ - that cause $x$ occurred

- Proposed conditions to carry out test

- Effects originally prompting $h_{\mathrm{x}}$

- Predicted test evidence, i.e., independent effects associated as narrowly as possible with conditions outlined in $h_{\mathrm{x}}$ should be observed.

[3] - Auxiliary theory(ies)

- Theory(ies) relevant to original effects

- Test conditions $a, b, c$, etc., established

- Predicted test evidence is observed/not observed pursuant to test conditions

- Hypothesis $h_{\mathrm{x}}$ is confirmed/disconfirmed.

What [1] represents is that, as a consequence of observing effect $e_{\mathrm{y}}$, one applies theory $X$ to infer that $e_{\mathrm{y}}$ is a consequence of some past causal condition(s) that is consistent with $X$. Note that abduction relies on the assumption that one is applying some previously accepted theory to effects. In the context of a field such as evolutionary biology, relevant theories would be those that have successfully withstood past testing, e.g., selection, genetic drift.

The act of hypothesis testing, i.e., [3], imposes the requirements that one witness test conditions that lead to confirming or disconfirming test evidence. To ensure the greatest severity of such a test, the test evidence sought should have the lowest probability of occurrence if the hypothesis being tested is not true (Peirce 1958; Mayo 1991, 1996; Cleland 2002, 2013), thereby offering the strongest test support. Are we in a position to legitimately test a hypothesis that relies upon a supernatural theory? This question presumes acceptance of the other premises comprising the test, especially the theory(ies) relevant to 
the hypothesis being tested. Accepting a supernatural theory as part of the premises in [1]-[3] assumes the theory has already been successfully tested. Indeed, such a theory(ries) would have been involved in the abductive inference of the hypothesis, cf. [1].

The example of abductive reasoning in [1] can be applied to the inferences of theories. In general, this involves analogical reasoning (Thagard 1988). For instance, Darwin (1859) made use the theory of artificial selection as the basis to abductively infer his theory of natural selection as the causal mechanism accounting for differentially shared characters among organisms. Regarding the subsequent process of theory testing, it has a form similar to hypothesis testing in [2] and [3], though there are fundamental differences that need to be noted. Recall that a theory asserts particular cause-effect relations. To test a theory, one must develop the relevant experiment (= test), whether contrived in a laboratory or under natural conditions, that allows the investigator to control as much as possible conditions under which the cause is manifested to minimize the chances of receiving spurious effects. In other words, one attempts to limit the possibilities of incurring effects that lead to 'false positive' or 'false negative' results (Cleland 2002), which is consistent with the preference for test evidence with the lowest probability of occurrence if the theory is not true. The schematic structure of inferring potential test evidence and subsequently testing a theory would have the respective forms,

[4] - Auxiliary theory(ies)

- Theory to be tested: theory $X$ - if cause $x$ occurs, effect $y$ will ensue

- Proposed test/experimental conditions allowing cause $x$ to occur

- Predicted test evidence, i.e., effect $y$ should be observed. 
[5] - Auxiliary theory(ies)

- Theory to be tested: theory $X$-if cause $x$ occurs, effect $y$ will ensue

- Test conditions established such that cause $x$ occurs

- Predicted test evidence, as effect $y$, is observed/not observed pursuant to the test conditions

- Hypothesis $h_{\mathrm{x}}$ is confirmed/disconfirmed.

Given the requirements for theory testing shown in [4] and [5], engaging in the testing of a supernatural theory would not be possible. If such a theory asserts that particular supernatural causes are at hand, an investigator, who is by definition limited to interacting with natural phenomena, is immediately precluded from either having available all relevant perceptual experiences of such causal conditions or manipulating such conditions for the purposes of minimizing spurious results. There are, however, claims that the theory of God has been tested and disconfirmed. For example, Stenger (2012, see also Stenger 2007) cites results analyzing the efficacy of intercessory prayer (e.g., Aviles et al. 2001) as an instance of an experiment assessing such a theory. Engaging in a protocol of prayer offers no legitimate test conditions that are sufficiently constrained to only consider causal interactions with a supernatural being. Regardless of the outcome of such a test purportedly confirming or disconfirming the presence of God as a causal agent, all the premises involved in the test (cf. [5]) are insufficient to establish the credibility of the result; a clear case of the Duhem-Quine problem (Gillies 1993). A similar problem was identified by Fitzhugh (2010) in assessing the claim by Behe (2001) that the theory of intelligent design can be tested in the laboratory in relation to the instantaneous acquisition of bacterial flagella.

This inherent limitation on testing is sidestepped in the intelligent design (ID) literature. In lieu of acknowledging abduction as reasoning from effects to tentative theories and explanatory hypotheses that require subsequent empirical testing, ID proponents have tended to focus on a perspective of abductive reasoning known as 'inference to the best explanation' or IBE as validating the utility of ID. IBE relies on the epistemological claim that one can proceed from abductive inference to a theory or hypothesis(es) to claiming the plausibility of that theory or hypothesis given considerations of explanatory criteria such as simplicity, explanatory scope, compatibility with background knowledge, predictive scope, etc., that warrant a theory or 
hypothesis to be the best among competing alternatives. But IBE is only a selection process subsequent to abduction; it is not inclusive of the later testing of those theories or hypotheses. Where ID's defense from abduction fails is that determining which among a set of competing hypotheses or theories is best will ultimately have to be settled by way of testing, which ID proponents have not sufficiently considered in defense of any theory of intelligent design.

As testing a supernatural theory is not technically feasible, testing a hypothesis inferred from such a theory would also be precluded. Note, however, that while supernatural-based hypotheses and theories are incorrigible, this does not prohibit entertaining alternative, empirical hypotheses and theories that are open to testing. Weighing the explanatory virtues of these alternatives is then a straightforward matter. Any empirical hypothesis or theory will have the benefit of testability, simplicity, and thus greater explanatory power relative to a supernatural hypothesis (Dawes 2009).

At this point, we can compare/contrast abductive inferences that are strictly scientific/natural and religious/supernatural in their respective scopes. Consistent with what Ruse (2008; quoted earlier) termed 'independent.' The former would have the form,

\section{[6] Natural}

- (Testable) auxiliary theory(ies)

- (Testable) scientific theory $T_{\mathrm{n}}$ : if (empirical) cause $x$ takes place, then (empirical) effect $y$ will ensue

- Observed effect $e_{\mathrm{n}}$ : phenomenon $y$

- (Potentially testable) hypothesis $h_{\mathrm{n}}$ : event $x$ occurred.

And the latter has the form, 


\section{[7] Supernatural}

-(Untestable) auxiliary theory(ies)

- (Untestable) God-based theory $T_{\mathrm{s}}$ : if (non-empirical) cause $u$ takes place, then (non-empirical) effect $v$ will ensue

-(Unobservable) effect $e_{\mathrm{s}}$ : phenomenon $v$

-(Untestable) hypothesis $h_{\mathrm{s}}$ : event $u$ occurred.

The labeling of the premises and conclusion 'untestable' in [7] is relative to an observer in the natural realm.

While a contrived example, it is significant to notice that supernatural-based theories and associated hypotheses in [7] only apply to non-empirical effects. As such effects are phenomena that lie beyond our perceptual abilities, the consequence is that the utility of [7] is obviated for our purposes. At best, the inference in [7] would only be relevant to a supernatural entity that can perceive supernatural cause-effect relations. The fact that the realm in which such relations would be manifested lies outside human perception, the premises and conclusion are beyond empirical testing.

In one sense, [6] and [7] are compatible in that both strive to pursue causal understanding. But the two inferences are incompatible from the perspective that the scientist is only allowed empirical access to [6] and precluded critiquing premises or conclusion in [7], per the requirements of scientific inquiry. This acknowledges the respective limitations on both classes of inquiry if [6] and [7] were consistently practiced. The accommodationist thesis, however, insists there is the alternative option where one can indeed implement [6] and a form of [7] to observed effects ${ }^{6}$. Claiming science and religion are not at odds with one another with respect to explanation carries with it the implication that one is able to arbitrarily forgo empirical theories in lieu of supernatural theories in the act of inferring explanatory hypotheses for natural phenomena ${ }^{7}$. Contra [6] and [7], the following inferential form would then be warranted:

\footnotetext{
${ }^{6}$ Thought experiments have their utility in the development of theories, not their empirical evaluation. For instance, Einstein used thought experiments to develop his theory of general relativity, but he then suggested how to test that (Barnett 2005).
} 
[8] - (Untestable) supernatural theory $T_{\mathrm{s}}$ : if (non-empirical) cause $u$ takes place, then (empirical) effect $y$ will ensue

- in lieu of (or vice versa) -

- (Testable) natural theory $T_{\mathrm{n}}$ : if (empirical) cause $x$ takes place, then (empirical) effect $y$ will ensue

- Observed effect $e_{\mathrm{n}}$ : phenomenon $y$

-(Untestable) hypothesis $h_{\mathrm{s}}$ : event $u$ occurred

- in lieu of (or vice versa) -

- (Potentially testable) hypothesis $h_{\mathrm{n}}$ : event $x$ occurred.

The alternative premises in [8] are necessitated for one to claim science and religion 'compatible' regarding the use of empirical and supernatural theories and hypotheses. But this presents four distinct predicaments for accommodationists. First, one must be willing to not only accept empirical theories that have survived past critical evaluation, but also willing to interject untestable, supernatural theories to explain empirical phenomena. Second, at the point methodological naturalism (cf., Boudry et al. 2010) is waived for explaining a instance, one has to accept that the cause-effect relations in successfully tested theories can be both arbitrarily violated and ignored in lieu of invoking supernatural theories. But as any supernatural theory is not available to being critically evaluated, one puts them self in the position of accepting a contradiction. The contradiction is incurred because the introduction of supernatural theories to explain empirical phenomena will result in one having to suspend application of one or more accepted empirical, scientific theories. Third, the arbitrary dismissal of empirical theories for supernatural will be by definition maximally irrational. ${ }^{8}$ No amount of empirical justification can be brought to bear on the situation. And fourth, the greatest problem with the contradiction to scientific practice in [8] is that it impedes the continued, critical acquisition of causal understanding over time. In fact, the accommodationist thesis is irresolvable since religious, supernatural theories are operationally immune to testing. The only option, if one wishes to minimize irrational understanding, would be to forgo supernatural theories altogether when causally

\footnotetext{
${ }^{8}$ The dismissal would be arbitrary for the fact that one can explain away all phenomena by supernatural causes as they may wish.
} 
considering all-natural phenomena.

\section{Conclusion - The Price of Compatibility}

Differential utilization of scientific (potentially testable/successfully tested) and supernatural theories and hypotheses (cf. [8]) will inevitably lead one to a position of causal understanding that is incompatible with the goal of scientific inquiry, or rational inquiry in general. The only way for science and religion to hold respective positions that are complementary is if their explanatory realms are wholly separate from one another with respect to empirical and nonempirical phenomena. The abductive inferences using scientific or religious theories in [6] and [7], respectively, stand as separate enterprises, as summarized in Figure 1A. In other words, supernatural theories and hypotheses apply to nonempirical effects (see [7]), and empirical theories and hypotheses are the only rational options accounting for natural effects (see [6]). The two classes of abductive reasoning are, in this instance, complementary for they pertain to their respective realms of reality. To claim, as accommodationists have, that science and religion are compatible neglects to make this strong distinction. The consequence is that it leaves open the option for considering supernatural theories as having explanatory relevance for whatever empirical phenomena one chooses to explain (cf., quotes from Ayala 2006, 2007 above) - a decisionmaking process that is at best arbitrary and at worst irrational and unproductive in the long run. Asserting compatibility of the form in [8] will ultimately lead to a contradiction with the accepted tenets of scientific inquiry, summarized in Figure 1B. The contradiction is for the fact that one must assume that accepted scientific theories can be circumvented for the sake of invoking supernatural theories that are beyond reproach.

A prominent attempt to endorse science-religion compatibility is the essay by Gould (1999: 56, 58, emphasis original), where he presented his "nonoverlapping magisteria (NOMA)" of science and religion:

"The lack of conflict between science and religion arises from a lack of overlap between their respective domains of professional expertise - science in the empirical constitution of the universe, and religion in the search for proper ethical values and the spiritual meaning of our lives...

The net of science covers the empirical universe: what is it made of (fact) and why does it work this way (theory). The net of religion extends over questions of moral meaning and value. These two magisteria do not overlap, nor do they encompass all inquiry (consider... the magisterium of art and the meaning of beauty)." 


\section{Causal realms}

\section{non-empirical/religious empirical/scientific (untestable theories) (confirmed theories)}



\section{A. compatible}

\section{Causal realms}

\section{non-empirical/religious empirical/scientific (untestable theories) (confirmed theories)}

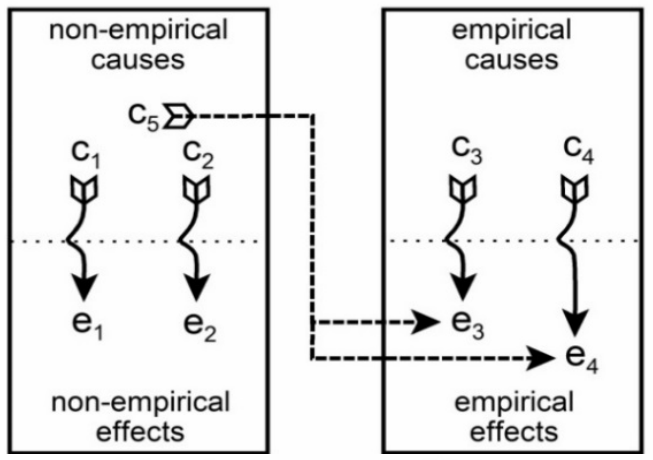

\section{B. incompatible}

Figure 1. Schematic representations of possible relations between scientific and religious explanatory contexts. A. The utility of entirely separate explanatory accounts for nonempirical and empirical phenomena is that the two causal realms are complementary (see text examples [6] and [7]). B. The accommodationist claim that science and religion are compatible is incorrect for the fact that supernatural theories are still seen as serving an explanatory function for empirical phenomena (see text example [8]). Under this type of relationship, science and religion are incompatible, as well as contradictory relative to 
scientific practice.

Although Gould (1999: 58) acknowledges that these NOMA "bump right up against each other," the way he characterizes their functions in human actions clearly shows that there is overlap of the form described in [8] (Figure 1B). For instance, to speak of "ethical values and the spiritual meaning of our lives" and "questions of moral meaning and value" (see also Ayala 2006, 2007) is to refer to actions among humans - actions that occur in the realm of the natural, and as such are empirically open to investigation and explanation by scientific inquiry. If religion is to explain these actions in the context of a supernatural entity as a causal factor, then the NOMA principal has been violated. The only way to say there is no conflict, thus compatibility and no contradiction with scientific practice, is to settle for the relations in Figure 1A (see [6] and [7]), which is not what Gould offered as a solution.

Like Gould (1999), Kurtz (2002) sees science and religion as compatible. But, Kurtz's reasoning does not suffer the defect of Gould's and Ayala's position of allowing religion qua the supernatural to lay causal claim on certain aspects of the human condition. Rather, Kurtz is clear in his conception of religion as being distilled down to the products of human thought. That is, religions are consequences of natural phenomena, in the same vein as discussed earlier regarding Dow's (2007) definition of religion (see also Wilson 1978; Dennett 2006; Ruse 2009; Thagard 2010; Thompson and Aukofer 2011). In his rendition, Kurtz (2002: 44) places religion squarely in the realm of reasoning shown in [6] and the right half of Figure 1A:

“...religious systems of belief, thought, emotion, and attitude are products of the creative human imagination. They traffic in fantasy and fiction, taking the promises of long-forgotten historical figures and endowing them with eternal cosmic significance."

Claiming science and religion are compatible implies contrary extremes. At one extreme the empirical and non-empirical can be interwoven to the extent one desires, as shown in [8] (Figure 1B). At the other extreme, all facets of understanding can only be attained by way of empirical, (potentially) testable causes that are open to continual evaluation, revision, and/or replacement; we must remain agnostic to the goings on in any causal realm beyond the natural. This latter extreme would encompass the respective realms depicted in [6] and [7] (Figure 1A). Given the tenets for conducting scientific inquiry, especially that we pursue causal understanding of natural phenomena by way of testable theories and hypotheses, there could be no allowance for the accommodationist view that science and religion are either not in conflict or are compatible, no matter the degree one chooses to parse those causal possibilities. To make an assertion of non-conflict or compatibility is to misrepresent the very foundations 
of how science is presently conceived. This conclusion is consistent with the lucid analysis by Peirce (1877; see also Almeder 1980) of the processes available for determining beliefs as consequences of inquiry. Peirce recognized that background knowledge predisposes one to having antecedent beliefs (Figure 2 ), and those beliefs lead to expectations of what should be observed in the future. When such expectations are not met, doubt ensues, which prompts the process of inquiry for the purpose of reestablishing stable beliefs. It was noted earlier (Causal Reasoning and Demise of Accommodationism) that whyquestions arise at the point one is confronted with unexpected effects, which leads to abductive reasoning to at least tentative answers to those questions (cf. [1]), thus establishing some degree of understanding. Why-questions and abduction are the instances of doubt and initial inquiry, respectively.

The relationships between these four methods in the context of the pursuit of belief are illustrated in Figure 2.



Figure 2. Summary of Peirce's (1877) examination of the relations between doubt, observation, and the four alternative methods used to fix beliefs. Peirce noted that religion falls within the method of authority. If, as accommodationists claim, science and religion are compatible, then the methods of authority and science would not be distinct approaches.

Peirce (1877) identified four methods for attaining beliefs via inquiry:

- method of tenacity - holding beliefs while refusing to consider evidence to the contrary;

- method of authority - relying on an authoritative institution for answers to questions; 
- method of the a priori - adopting an opinion on inclination, taste, fashion, etc;

- method of science - beliefs determined from available evidence that is external to the individual.

Of these methods, Peirce observed that only the method of science offers the prospect of establishing, in the long run, stable beliefs that are true. Attaining such stability is a product of the continual process of belief revision pursuant to the process of testing, and testing requires the acquisition of evidence independent of individuals holding those beliefs:

"To satisfy our doubts, therefore, it is necessary that a method should be found by which our beliefs may be caused by nothing human, but by some external permanency - by something upon which our thinking has no effect."

In contrast, it is through the method of authority that religion operates, requiring acceptance of beliefs that are inferential products offering some degree of understanding, but those beliefs are not, or cannot be, subjected to empirical scrutiny. Peirce recognized that science and religion achieve beliefs in distinctly different ways, and his relegation of religion to the method of authority rather than the method of science is to be expected if scientific and religious inquiry are not compatible and are conflicting 'ways of knowing.'

Accepting that science and religion are incompatible as explanatory options is not an indictment against either enterprise or the practice of both by an individual. There are no rules of logic that demand that considerations of the supernatural as a causal factor relative to natural phenomena be precluded, or that only natural causes can be entertained, regardless of the intellectual cost to the inquirer. The point of this essay is, instead, that science only deals with empirical causation and to the detriment of rational inquiry, religion affords us opportunities to deal with both non-empirical and empirical causation, especially in the case of non-empirical theories and causes explaining empirical phenomena. That one can seek causal understanding utilizing supernatural theories in lieu of natural theories is a matter of personal choice that transcends logic per se; it is a condition determined as a matter of common sense. But in making that choice, practitioners must recognize that it will be one that is less than minimally irrational in the extreme and at odds with established scientific practice. It is for this reason that the demand for methodological naturalism in science, to which end the goal is the continual increase in causal understanding, is not compatible with what is allowed by way of religious causal understanding. To claim otherwise is to misrepresent science - the essence of the error committed by advocates of accommodationism. 


\section{Literature Cited}

Achinstein, P. 1970. Inference to scientific laws. In, Stuewer, R. H. Editor. pp. 87-111. Historical and Philosophical Perspectives of Science. Volume V. University of Minnesota Press. Minneapolis, Minnesota, USA. 384 pp.

Aliseda, A. 2006. Abductive Reasoning: Logical Investigations into Discovery and Explanation. Springer. Dordrecht, The Netherlands. 245 pp. https://link-springercom.ezaccess.libraries.psu.edu/content/pdf/10.1007\%2F1-4020-3907-7.pdf

Almeder, R. 1980. The Philosophy of Charles S. Peirce: A Critical Introduction. Basil Blackwell. Oxford, England, UK. 205 pp.

Anonymous Contributors. 2006. Statement on the Teaching of Evolution. American Association for the Advancement of Science. Washington, District of Columbia, USA. Available at https://www.aaas.org/sites/default/files/s3fs-public/0219boardstatement.pdf . Accessed 27 October 2018.

Anonymous Contributors. 2008a. Compatibility of Science and Religion. National Academies of Sciences, Engineering [, and] Medicine. United States National Academy of Sciences. 2008. http://www.nationalacademies.org/evolution/Compatibility.html . Accessed 27 October, 2018.

Anonymous Contributors. 2008b. Science, Evolution, and Creationism. Institute of Medicine. National Academy of Sciences. The National Academies Press. Washington, District of Columbia, USA. $70 \mathrm{pp}$.

Anonymous Contributors. 2009a. Misconceptions about evolution. https://evolution.berkeley.edu/evolibrary/misconceptions faq.php In, Understanding Evolution. University of California Museum of Paleontology. Berkeley, California, USA. https://evolution.berkeley.edu/evolibrary/home.php . Accessed 27 October 2018.

Anonymous Contributors. 2009b. How science really works. In, Understanding Science. University of California Museum of Paleontology. Berkeley, California, USA. http://undsci.berkeley.edu/article/science_religion. Accessed 27 October 2018.

Anonymous Contributors. 2011. Dialogue on science, ethics, and religion. In, Scientists in Civic Life. Facilitating Dialogue-Based Communication. American Association for the Advancement of Science. Washington, District of Columbia, USA. https://www.aaas.org/programs/dialoguescience-ethics-and-religion . Accessed 27 October, 2018.

Aviles, J. M., A. Whelan, D. A. Hernke, B. A. Williams, K. E. Kenny, W. M. O'Fallon, and S. L. Kopecky. 2001. Intercessory prayer and cardiovascular disease progression in a coronary care unit population: a randomized controlled trial. Mayo Clinic Proceedings 76:1192-1198. https://doi.org/10.4065/76.12.1192

Avise, J. C. 2010a. Inside the Human Genome: A Case for Non-Intelligent Design. Oxford University Press. New York, NY, USA. 222 pp. https://doi.org/10.1093/acprof:oso/9780195393439.001.0001

Avise, J. C. 2010b. Footprints of nonsentient design inside the human genome. Proceedings of the National Academy of Science 107 (Supplement 2): 8969-8976. https://doi.org/10.1073/pnas.0914609107

Ayala, F. J. 2006. Darwin and Intelligent Design. Fortress Press. Minneapolis, Minnesota, USA. 116 $\mathrm{pp}$.

Ayala, F. J. 2007. Darwin's Gift to Science and Religion. Joseph Henry Press and National Academy of Sciences. Washington, District of Columbia, USA. 237 pp.

Ayala, F. J. 2008. Darwin's gift to science and religion: commentaries and responses. Theology and Science 6:179-196. https://doi.org/10.1080/14746700801976932

Barnett, L. 2005. The Universe and Dr. Einstein. Dover Publications. Mineola, New York, USA. $128 \mathrm{pp}$.

Behe, M. J. 2008. Can a scientific theory ameliorate a theological difficulty? Theology and Science 6: 147-152. https://doi.org/10.1080/14746700801976858

Ben-Menahem, Y. 1990. The inference to the best explanation. Erkenntnis 33:319-344. https://doi.org/10.1007/BF00717590

Boudry, M., S. Blancke, S., and J. Braeckman. 2010. How not to attack intelligent design creationism: philosophical misconceptions about methodological naturalism. Foundations of 
Science 15: 227-244. https://doi.org/10.1007/s10699-010-9178-7

Cleland, C. E. 2002. Methodological and epistemic differences between historical science and experimental science. Philosophy of Science 69:474-496. https://doi.org/10.1086/342455

Cleland, C. E. 2013. Common cause explanation and the search for a smoking gun. The Geological Society of America Special Paper 502 1-9. https://doi.org/10.1130/2013.2502(01)

Copi, I. M. and C. Cohen. 1998. Introduction to Logic. Tenth Edition. Prentice Hall. Upper Saddle River, New Jersey, USA. 714 pp.

Coyne, J. A. 2012. Science, religion, and society: the problem of evolution in America. Evolution 66:2654-2663. https://doi.org/10.1111/j.1558-5646.2012.01664.x

Curd, M. V. 1980. The logic of discovery: an analysis of three approaches. In, T. Nickles (Editor). pp. 201-219. Scientific Discovery, Logic and Rationality. D. Reidel Publishing Company. Dordrecht, The Netherlands. 334 pp. https://doi.org/10.1007/978-94-009-8986-3 8

Dawes, G. W. 2009. Theism and Explanation. Routledge. New York, NY, USA. 211 pp.

Dennett, D. C. 2006. Breaking the Spell: Religion as a Natural Phenomenon. Viking. New York, NY, USA. 448 pp.

de Regt, H. W. 2017. Understanding Scientific Understanding. Oxford University Press. New York, NY, USA. 301 pp. https://doi.org/10.1093/oso/9780190652913.001.0001

de Regt, H. W., S. Leonelli, and K. Eigner. 2009. Focusing on scientific understanding. In, H. W. de Regt, S. Leonelli, and K. Eigner (Editors). pp. 1-17. Scientific Understanding: Philosophical Perspectives. University of Pittsburgh Press. Pittsburgh, Pennsylvania, USA. 365 pp. https://doi.org/10.2307/j.ctt9qh59s.4

Douven, I. 2002. Testing inference to the best explanation. Synthese 130:355-377. https://doi.org/10.1023/A:1014859910339

Dow, J. W. 2007. A scientific definition of religion. Anthropological Perspectives on Religion. http://www.anpere.net/2007/2.pdf

Ecklund, E. H. 2010. Science vs. Religion: What Scientists Really Think. Oxford University Press. New York, NY, USA. 228 pp. https://doi.org/10.1093/acprof:oso/9780195392982.001.0001

Ecklund, E. H. and J. Z. Park. 2009. Conflict between religion and science among academic scientists? Journal for the Scientific Study of Religion 48:276-292. https://doi.org/10.1111/j.1468-5906.2009.01447.x

Fann, K. T. 1970. Peirce's Theory of Abduction. Martinus Nijhoff. The Hague, The Netherlands. 70 pp. https://doi.org/10.1007/978-94-010-3163-9

Fitzhugh, K. 2005a. The inferential basis of species hypotheses: the solution to defining the term 'species.' Marine Ecology 26:155-165. https://doi.org/10.1111/j.1439-0485.2005.00058.x

Fitzhugh, K. 2005b. Les bases philosophiques de l'inférence phylogénétique: une vue d'ensemble. Biosystema 24:83-105.

Fitzhugh, K. 2006a. The abduction of phylogenetic hypotheses. Zootaxa 1145, 1-110.

Fitzhugh, K. 2006b. The 'requirement of total evidence' and its role in phylogenetic systematics. Biology \& Philosophy 21, 309-351. https://doi.org/10.1007/s10539-005-7325-2

Fitzhugh, K. 2006c. The philosophical basis of character coding for the inference of phylogenetic hypotheses. Zoologica Scripta 35, 261-286. https://doi.org/10.1111/j.1463-6409.2006.00229.x

Fitzhugh, K. 2008a. Fact, theory, test and evolution. Zoologica Scripta 37:109-113.

Fitzhugh, K. 2008b. Abductive inference: implications for 'Linnean' and 'phylogenetic' approaches for representing biological systematization. Evolutionary Biology 35:52-82. https://doi.org/10.1007/s11692-008-9015-x

Fitzhugh, K. 2008c. Clarifying the role of character loss in phylogenetic inference. Zoologica Scripta 37:561-569. https://doi.org/10.1111/j.1463-6409.2008.00338.x

Fitzhugh, K. 2009. Species as explanatory hypotheses: refinements and implications. Acta Biotheoretica 57:201-248. https://doi.org/10.1007/s10441-009-9071-3

Fitzhugh, K. 2010. Evidence for evolution versus evidence for intelligent design: parallel confusions. Evolutionary Biology 37:68-92. https://doi.org/10.1007/s11692-010-9088-1

Fitzhugh, K. 2016. Sequence data, phylogenetic inference, and implications of downward causation. Acta Biotheoretica 64:133-60. https://doi.org/10.1007/s10441-016-9277-0

Geertz, C. 1993. Religion as a cultural system. In, C. Geertz (Editor). pp. 87-125. The Interpretation 
of Cultures: Selected Essays. Fontana Press. London, England, UK. 470 pp.

Gillies, D. 1993. Philosophy of Science in the Twentieth Century: Four Central Themes. Blackwell Publishers. Cambridge, England, UK. 251 pp.

Godfrey-Smith, P. 2003. Theory and Reality: An Introduction to the Philosophy of Science. University of Chicago Press. Chicago, Illinois, USA. 272 pp. https://doi.org/10.7208/chicago/9780226300610.001.0001

Gould, S. J. 1999. Non-overlapping magisteria. Skeptical Inquirer 23(4):55-61.

Hacking, I. 2001. An Introduction to Probability and Inductive Logic. Cambridge University Press. New York, NY, USA. 302 pp. https://doi.org/10.1017/CBO9780511801297

Hanson, N. R. 1958. Patterns of Discovery: An Inquiry into the Conceptual Foundations of Science. Cambridge University Press. New York, NY, USA. 240 pp.

Harman, G. 1965. The inference to the best explanation. The Philosophical Review 4:88-95. https://doi.org/10.2307/2183532

Hausman, D. M. 1998. Causal Asymmetries. Cambridge University Press. New York, NY, USA. 300 pp. https://doi.org/10.1017/CBO9780511663710

Hempel, C. G. 1965. Aspects of Scientific Explanation and Other Essays in the Philosophy of Science. The Free Press. New York, NY, USA. 505 pp.

Hull, D. 1974. Philosophy of Biological Science. Prentice-Hall, Inc. Englewood Cliffs, California, USA. $148 \mathrm{pp}$.

Josephson, J. R. and S. G. Josephson, S. (Editors). 1994. Abductive Inference: Computation, Philosophy, Technology. Cambridge University Press. New York, NY, USA. 306 pp. https://doi.org/10.1017/CBO9780511530128

Kurtz, P. 2002. Are science and religion compatible? Skeptical Inquirer 26(2):42-45.

Lipton, P. 2004. Inference to the Best Explanation. Routledge. New York, NY, USA. 194 pp.

Magnani, L. 2001. Abduction, Reason, and Science: Processes of Discovery and Explanation. Kluwer Academic/Plenum Publishers. New York, NY, USA. 205 pp. https://doi.org/10.1007/978-1-4419-8562-0

Mahner, M., and M Bunge. 1997. Foundations of Biophilosophy. Springer. New York, NY, USA. 423 pp. https://doi.org/10.1007/978-3-662-03368-5

Martin, J. W. 2010. The Prism and the Rainbow: A Christian Explains Why evolution is Not a Threat. The Johns Hopkins University Press. Baltimore, Maryland, USA. 170 pp.

Mayo, D. G. 1991. Novel evidence and severe tests. Philosophy of Science 58:523-552. https://doi.org/10.1086/289639

Mayo, D. G. 1996. Error and the Growth of Experimental Knowledge. University of Chicago Press. Chicago, Illinois, USA. 495 pp. https://doi.org/10.7208/chicago/9780226511993.001.0001

McMullin, E. 1995. The Inference that Makes Science. Marquette University Press. Milwaukee, Wisconsin, USA. $117 \mathrm{pp}$.

Meyer, S. C. 1999. The return of the God hypothesis. Journal of Interdisciplinary Studies 11:1-38.

Meyer, S. C. 2013. Darwin's Doubt: The Explosive Origin of Animal Life and the Case for Intelligent Design. HarperOne. New York, NY, USA. 498 pp.

Moritz, J. M. 2009. Rendering unto science and God: is NOMA enough? Theology and Religion 7:363-378. https://doi.org/10.1080/14746700903239510

Nickles, T. 1980. Introductory essay: scientific discovery and the future of philosophy of science. pp. 1-59. In, Nickles, T. (Editor). Scientific Discovery, Logic and Rationality. D. Reidel Publishing Company. Dordrecht, The Netherlands. 385 pp. https://doi.org/10.1007/978-94009-8986-3 1

Peirce, C. S. 1877. The fixation of belief. Popular Science Monthly 12:1-15.

Peirce, C. S. 1878. Illustrations of the logic of science. Sixth paper. - Deduction, induction, and hypothesis. Popular Science Monthly 13:470-482.

Peirce, C. S. 1931. Collected Papers of Charles Sanders Peirce. Volume 1. Principles of Philosophy. In, C. Hartshorne, P. Weiss, and A. Burks (Editors). Harvard University Press. Cambridge, Massachusetts, USA. 393 pp. 
Peirce, C. S. 1932. Collected Papers of Charles Sanders Peirce. Volume 2. Elements of Logic. In, C. Hartshorne, P. Weiss, and A. Burks (Editors). Harvard University Press. Cambridge, Massachusetts, USA. 535 pp.

Peirce, C. S. 1933a. Collected Papers of Charles Sanders Peirce. Volume 3. Exact Logic. In, C. Hartshorne, P. Weiss, and A. Burks (Editors). Harvard University Press. Cambridge, Massachusetts, USA. 433 pp.

Peirce, C. S. 1933b. Collected Papers of Charles Sanders Peirce. Volume 4. The Simplest Mathematics. In, C. Hartshorne, P. Weiss, and A. Burks (Editors). Harvard University Press. Cambridge, Massachusetts, USA. 601 pp.

Peirce, C. S. 1934. Collected Papers of Charles Sanders Peirce. Volume 5. Pragmatism and Pragmaticism. In, C. Hartshorne, P. Weiss, and A. Burks (Editors). Harvard University Press. Cambridge, Massachusetts, USA. 455 pp.

Peirce, C. S. 1935. Collected Papers of Charles Sanders Peirce. Volume 6. Scientific Metaphysics. In, C. Hartshorne, P. Weiss, and A. Burks (Editors). Harvard University Press. Cambridge, Massachusetts, USA. 462 pp.

Peirce, C. S. 1958a. Collected Papers of Charles Sanders Peirce. Volume 7. Science and Philosophy. In, C. Hartshorne, P. Weiss, and A. Burks (Editors). Harvard University Press. Cambridge, Massachusetts, USA. 415 pp.

Peirce, C. S. 1958b. Collected Papers of Charles Sanders Peirce. Volume 8. Correspondence and Bibliography. In, A. Burks (Editor). Harvard University Press. Cambridge, Massachusetts, USA. 352 pp.

Popper, K. R. 1983. Objective Knowledge: An Evolutionary Approach. Oxford University Press. New York, NY, USA. 395 pp.

Popper, K. R. 1992. Realism and the Aim of Science. Routledge. New York, NY, USA. 420 pp.

Psillos, S. 2002. Simply the best: a case for abduction. In, A. C. Kakas and F. Sadri (Editors), Computational Logic: Logic Programming and Beyond. Springer. New York, NY, USA. 678 pp. https://doi.org/10.1007/3-540-45632-5_24

Pyysiäinen, I. and M. Hauser. 2010. The origins of religion: evolved adaptation or by-product? Trends in Cognitive Sciences 14:104-109. https://doi.org/10.1016/i.tics.2009.12.007

Reilly, F. E. 1970. Charles Peirce's Theory of Scientific Method. Fordham University Press. New York, NY, USA. 200 pp.

Rescher, N. 1970. Scientific Explanation. The Free Press. New York, NY, USA. 242 pp.

Ruse, M. 2008. An evolutionist thinks about religion. Theology and Science 6:165-171. https://doi.org/10.1080/14746700801976890

Ruse, M. 2009. Defining Darwin: Essays on the History and Philosophy of Evolutionary Biology. Amherst: Prometheus Books. Amherst, Massachusetts, USA. 271 pp.

Salmon, W. C. 1967. The Foundations of Scientific Inference. University of Pittsburgh Press. Pittsburgh, Pennsylvania, USA. 157 pp. https://doi.org/10.2307/j.ctt5hjqm2

Salmon, W. C. 1984a. Scientific Explanation and the Causal Structure of the World. Princeton University Press. Princeton, New Jersey, USA. 305 pp.

Salmon, W. C. 1984b. Logic. Prentice-Hall, Inc. Englewood Cliffs, New Jersey, USA. 180 pp.

Salmon, W. C. 1989. Four decades of scientific explanation. In, Kitcher, P. and W. C. Salmon (Editors). pp. 3-219. Volume XIII, Scientific Explanation. Minnesota Studies in the Philosophy of Science. University of Minnesota Press. Minneapolis, Minnesota, USA. 528 pp.

Shermer, M. 2000. How We Believe: The Search for God in an Age of Science. W. H. Freeman. New York, NY, USA. 302 pp.

Sober, E. 1986. Explanatory presupposition. Australasian Journal of Philosophy 64:143-149. https://doi.org/10.1080/00048408612342351

Sober, E. 1994. From a Biological Point of View: Essays in Evolutionary Biology. Cambridge University Press. New York, NY, USA. 255_pp. https://doi.org/10.1017/CBO9780511624940

Stenger, V. J. 2007. God: The Failed Hypothesis: How Science Shows that God Does Not Exist. Prometheus Books. Amherst, Massachusetts, USA. 294 pp.

Stenger, V. 2012. The God Hypothesis. HoftPost. Oath Inc. http://www.huffingtonpost.com/victorstenger/the-god-hypothesis_b_1355321.html. Accessed 27 October 2018. 
Thagard, P. 1988. Computational Philosophy of Science. Cambridge: The MIT Press. Cambridge, Massachusetts, USA. 240 pp.

Thagard, P. 2010. The Brain and the Meaning of Life. Princeton University Press. Princeton, New Jersey, USA. 200 pp. https://doi.org/10.1515/9781400834617

Thompson, J. A. and C. Aukofer. 2011. Why We Believe in God(s): A Concise Guide to the Science of Faith. Pitchstone Publishing. Charlottesville, Virginia, USA. 144 pp.

Van Fraassen, B. C. 1990. The Scientific Image. Clarendon Press. Oxford, England, UK. 235 pp.

Walton, D. 2004. Abductive Reasoning. The University of Alabama Press. Tuscaloosa, Alabama, USA. 303 pp.

Wilson, E. O. 1978. On Human Nature. Harvard University Press. Cambridge, Massachusetts, USA. $260 \mathrm{pp}$. 